\title{
KONTRIBUSI LOCUS OF CONTROL DAN PERFEKSIONIS TERHADAP PROKRASTINASI AKADEMIK SISWA SERTA IMPLIKASINYA DALAM PELAYANAN BIMBINGAN DAN KONSELING DI SMAN 10 PADANG
}

\author{
Desy Murni Lasari1, Marjohan2, Yeni Karneli3
}

\begin{abstract}
Academic procrastination was one of behavior of students who defer to the task. Academic procrastination was influenced by various factors among which are the locus of control and perfectionist. This study aimed to described: (1) locus of control of students SMAN 10 Padang, (2) perfectionist of students SMAN 10 Padang, (3) academic procrastination of students SMAN 10 Padang, (4) contribution locus of control toward academic procrastination students SMAN 10 Padang, (5) contribution of perfectionist towardacademic procrastination studentsSMAN 10Padang, (6) contribution locus of control and perfectionist toward academic procrastination students SMAN 10 Padang.This study used a quantitative approach with descriptive correlational method. The population in this research were students in grade X and XI of SMAN 10 Padang many as 571 students. Samples were obtained as many 235 students with using Proportional Stratified Random Sampling technique. The instruments of this research were the Inventory and Likert scale model. The data obtained were analyzed by using simple regression, and multiple regression.The research finding were: (1) locus of control in average were at internal category, (2) perfectionist in average were atmoderate category, (3) the academic procrastination in average were at moderate category, (4) the locus of control are contribution significant to academic procrastination by $21.3 \%$, (5) the perfectionist contribution significant to academic procrastination by $11.7 \%$, and (6) the locus of control and perfectionist in together contribute significant to the academic procrastination by $24.5 \%$. The implication of this research may useful input to direct the Guidance and Counseling Teacher/Counselors to provide guidance and counseling services especially for personal and of study field.
\end{abstract}

Keywords: Locus of Control, Perfectionist, Academic Procrastination

\section{PENDAHULUAN}

Belajar merupakan kewajiban yang harus dipenuhi oleh siswa. Siswa sebagai subjek belajar di sekolah tentunya dituntut untuk memiliki pengelolaan waktu belajar yang baik dalam mengerjakan tugas-tugas yang diberikan oleh guru sehingga membutuhkan pemanfaatan waktu secara baik, agar semua kegiatannya dapat berjalan dengan efektif dan efisien.

$$
\text { Akinsola \& Tella (2007:364) }
$$

menjelaskan bahwa "The target-oriented student objectives are to get good grades and commit to reach that goal and exercise behaviors such as focusing on difficult tasks, completed all assignments, manage time carefully, and gets help when needed". Penjelasan di atas, dapat disimpulkan bahwa target utama yang dilakukan siswa dalam belajar adalah mendapatkan nilai yang baik dan berkomitmen untuk mencapai tujuan dan latihan perilaku seperti: fokus pada tugastugas yang sulit, melengkapi semua tugas, mengatur waktu dengan hati-hati, dan mencari bantuan bila membutuhkan. Namun, kenyataan yang terjadi masih ada siswa yang belum mampu memanfaatkan waktu belajar, baik di rumah maupun di sekolah dalam mengerjakan tugas, sehingga siswa melakukanpenundaan.

$$
\text { Menurut Rumiani }
$$

kecenderungan individu dalam menunda dan melaksanakan suatu aktivitas atau pekerjaan disebut dengan prokrastinasi. Selanjutnya, Senecal, Koestner, \& Vallerand (dalam Gohil, 2014:92) mendefinisikan bahwa "Academic procrastination can be understood as knowing that one is supposed 
to, and perhaps even wanting to, complete an academic task but failing to perform the activity within the expected or desired time frame". Kutipan di atas, mengungkapkan prokrastinasi akademik merupakan salah satu penundaan yangseharusnya mengerjakan tugas atau menyelesaikan tugas akademik, akan tetapi gagal untuk melakukannya, dalam jangka waktu yang diharapkan atau diinginkan. Solomon \& Rothblum (1984) menjelaskan kerugian yang dihasilkan dari perilaku prokrastinasi adalah tugas tidak terselesaikan, atau terselesaikan namun hasilnya tidak maksimal karena sudah deadline, menimbulkan kecemasan sepanjang waktu pengerjaan tugas, sehingga jumlah kesalahan cenderung tinggi karena individu mengerjakan dalam waktu yang sempit. Selanjutnya,Burka \& Yuen (2008) menjelaskan setiap individu tua maupun muda, pengangguran atau profesional yang sukses, dapat menjadi prokrastinator, karena prokrastinasi tidak membeda-bedakan atas dasar ras, kepercayaan, jenis kelamin, ataupun suku bangsa.

Hasil penelitian Savira \& Suharsono (2013) menunjukkan bahwa siswa melakukan prokrastinasi akademik yang tinggi sebesar 52,1\%, artinya siswa yang menunda-nunda mengerjakan tugas, terlambat mengerjakan tugas, tidak sesuai dengan deadline yang telah ditetapkan, dan mendahulukan aktivitas lain saat menyelesaikan tugas. Sedangkan, sisanya sebesar $47,9 \%$ tergolong pada prokrastinasi akademik rendah. Selanjutnya, hasil penelitian Juliawati (2014) pada salah satu sekolah di Kota Padang ditemukan bahwa kecenderungan prokrastinasi akademik siswa berada pada kategori tinggi dengan persentase $60 \%$, kemudian prokrastinasi akademik berada pada kategori sedang dengan persentase $20 \%$, dan prokrastinasi akademik berada pada kategori rendah dengan persentase $20 \%$.

Berdasarkan hasil observasi yang peneliti lakukan di SMAN 10 Padang pada bulan Mei 2016, ditemukan bahwa banyak siswa melakukan prokrastinasi dalam belajar.
Hal ini terbukti dari cara siswa mengerjakan tugas yaitu: siswa sering menunda-nunda dalam memulai dan menyelesaikan tugas yang diberikan guru, terlambat dalam pengumpulan tugas, meminta waktu untuk perpanjangan pengumpulan tugas, mengerjakan tugas lain di saat jam pelajaran berlangsung, merasa cemas karena tugas belum selesai, sehingga menyebabkan siswa terlambat masuk kelas untuk mengikuti pelajaran. Selanjutnya, hasil wawancara dengan Guru BK/Konselor, ditemukan bahwa siswa mengalami penurunan pada nilai-nilai rapor, padahal siswa merasa mampu dan sanggup ketika melakukan pembelajaran di dalam kelas.

Dari beberapa permasalahan di atas, siswa yang melakukan prokrastinasi dipengaruhi oleh berbagai faktor.Ackerman, Gross, Phillips, Jory, \& Mogford (dalam Gafni \& Geri, 2010) mengungkapkan prokrastinasi akademik di pengaruhi oleh kurangnya motivasi, kurangnya pengaturan diri, lokus kendali eksternal, perfeksionis, disorganisasi, dan manajemen waktuyang buruk.

Prokrastinasi akademik dipengaruhi oleh banyak faktor salah satunyalocus of control. Rotter (dalam Loice, 2014:02) mendefinisikan bahwa "Locus of control as the extent to which people perceived that them or external factors such as chance and powerful others are in control of the events that influence their lives". Locus of control dilihat dari sejauh mana individu merasa bahwa dirinya (faktor internal) atau faktor dari luar dirinya (faktor eksternal), seperti kesempatan dan kekuatan lain, dapat mengendalikan peristiwa yang terjadi dan mempengaruhi kehidupan mereka.Menurut Rotter (1966)locus of control terdiri dari dua dimensi, yaitu internal dan eksternal, siswa yang memiliki kecenderungan internal locus of control meyakini bahwa kesuksesan dan kegagalannya dalam belajar adalah hasil dari tindakan dan usaha mereka sendiri. Sebaliknya, siswa yang memiliki kecenderungan external locus of control akan meyakini bahwa kesuksesan dan 
kegagalannya adalah karena faktor dari luar dirinya.

Penelitian Nugrasanti (2006) tentang hubungan antara locus of control dan prokrastinasi akademik pada mahasiswa, hasil perhitungan korelasi antara kedua variabel menunjukkan hubungan yang signifikan, yakni semakin external locus of control mahasiswa, maka semakin tinggi kecenderungan prokrastinasi akademik yang dilakukannya.

Berdasarkan hasil observasi yang dilakukan di SMAN 10 Padang pada bulan Mei 2016, masih banyak siswa yang kurang meyakinikemampuannya dalammengerjakan tugas, ketidakmampuan dirinya dalam mengatur waktu belajar yang baik, dan kurang inisiatif dalam menyelesaikan masalah maupun tugas yang diberikan oleh guru, sehingga siswa cenderung melakukan prokrastinasi dalam mengerjakan tugas.

Selain locus of control, faktor lain yang juga menyebabkan siswa melakukan prokrastinasi akademik adalah perfeksionis. Menurut Flett \& Hewitt, 2002; Blankstein \& Dunkley, 2002 (dalam Yang \& Stoeber, 2012:3) "Perfectionist is a personality disposition characterized by striving for flawlessness and exceedingly high personal standards accompanied by overly critical self-evaluations and concerns about others evaluations". Perfeksionis adalah karakteristik kepribadian yang ditandai dengan keinginan yang sempurna dan standar pribadi yang sangat tinggi, disertai dengan terlalu kritis dalam menilai diri dan kekhawatiran tentang evaluasi orang lain. Selanjutnya, menurut Burka \& Yuen (2008) keyakinan-keyakinan irasional yang membawa pada perilaku prokrastinasi. Pertama, individu yang perfeksionis percaya bahwa dirinya dapat melakukan segala sesuatu secara sempurna tanpa ada kesalahan. Kedua, individu yang perfeksionis memiliki keyakinan bahwa menerima bantuan dari orang lain adalah suatu kelemahan, seberat apapun tugas yang diberikan padanya akan dikerjakan seorang diri. Pada akhirnya, ketidakmampuan untuk melakukan segala sesuatu seorang diri membuatnya memutuskan melakukan prokrastinasi.

Hamachek (dalam Hawkins, Watt, \&Sinclair, 2006:101) mengungkapkan "Asserted that the efforts of neurotic perfectionists "Never seem good enough, at least in their own eyes they are unable to feel satisfaction because in their own eyes they never seem to do things good enough to warrant that feeling". Pendapat di atas, menjelaskan perfeksionis dibagi dalam dua jenis, yaitu perfeksionis normal dan neorotik. Perfeksionis normal dijelaskan sebagai seseorang yang memperoleh perasaan kesenangan atau kenikmatan yang sangat nyata dari usaha kerja yang sungguhsungguh, sedangkan perfeksionis neorotik adalah seseorang yang tidak pernah merasa puas atas apa yang telah dilakukannya, dalam pandangan mereka tidak pernah cukup baik yang sesuai dengan keinginan mereka.

Hasil penelitian Flett, Blankstein, Hewitt, \& Koledin (1992) menunjukkan perfeksionis memiliki hubungan dengan prokrastinasi akademik dan lebih bergantung kepada konteks sosial.

Berdasarkan hasil observasi yang dilakukan di SMAN 10 Padang pada bulan Mei 2016, ditemukan: siswa merasa cemas dengan tugas yang akan dikerjakan tidak sesuai dengan harapan, siswa tidak bertanya dengan teman tentang tugas yang tidak paham, besarnya keinginan untuk mengerjakan tugas tanpa ada kesalahan, mencari bahan-bahan yang diperlukan hingga tiba batas pengumpulan, mengerjakan tugas berat seorang diri tanpa berdiskusi dengan teman sekelas, dan selalu merasa ada yang salah pada setiap tugas yang dikerjakan.

Berdasarkan uraian di atas, terlihat adanya keterkaitan locus of control siswa dan perfeksionis secara bersama-sama berkontribusi terhadap prokrastinasi akademik. Namun, bagaimana besar kecilnya kontribusi antara faktor-faktor tersebut, maka perlu dilakukan penelitian. Hasil dari penelitian inilah yang akan dijadikan acuan dalam menganalisis kebutuhan untuk 
penyusunan program BK. Hal inilah yang menjadi dasar penelitian ini dilakukan, karena belum adanya temuan penelitian yang menunjukkan seberapa besar kontribusi locus of control dan perfeksionis terhadap prokrastinasi akademik siswa di SMAN 10 Padang.

Tujuan penelitian ini untuk mendeskripsikan: (1) locus of control siswa SMAN 10 Padang, (2) perfeksionis siswa SMAN 10 Padang, (3) prokrastinasi akademik siswa SMAN 10 Padang, (4) kontribusi locus of control terhadap prokrastinasi akademik siswa SMAN 10 Padang, (5) kontribusi perfeksionis terhadap prokrastinasi akademik siswa SMAN 10 Padang, dan (6) kontribusi locus of control dan perfeksionis terhadap prokrastinasi akademik siswa SMAN 10 Padang.

\section{METODOLOGI}

Penelitian ini menggunakan metode kuantitatif jenis deskriptif korelasional. Populasi penelitian adalah siswa kelas X dan XI SMAN10 Padang berjumlah 571 siswa, dengan sampel 235 dengan teknik proportional stratified random sampling. Instrumen yang digunakan adalah skala model Likert dan inventory. Untuk mengetahui kontribusi variabel bebas terhadap variabel terikat, maka data dianalisis dengan regresi sederhana dan regresi ganda. Analisis data dengan menggunakan program SPSS versi 20.0.

\section{HASIL PENELITIAN}

\section{Deskripsi Data}

Data dalam penelitian ini meliputi variabel locus of control $\left(\mathrm{X}_{1}\right)$, perfeksionis $\left(\mathrm{X}_{2}\right)$, dan prokrastinasi akademik (Y). Berikut ini dikemukakan deskripsi data hasil penelitian.

\section{Locus of Control $\left(\mathrm{X}_{1}\right)$}

Deskripsi data locus of control yang berjumlah 235 siswa, dapat dilihat pada Tabel 1.
Tabel 1. Distribusi Frekuensi dan Persentase Locus of Control $\left(\mathrm{X}_{1}\right)$

\begin{tabular}{|c|c|c|c|}
\hline Kategori & Skor & f & $\%$ \\
\hline Intermal & $\leq 11,5$ & 148 & 63 \\
\hline Ekstemal & $>11,5$ & 87 & 37 \\
\hline \multicolumn{2}{|c|}{ Total } & 235 & 100 \\
\hline
\end{tabular}

Tabel 1 memperlihatkan bahwa siswa SMAN 10 Padang memiliki kecenderungan internal locus of control. Namun dengan demikian, masih terdapat variasi skor locus of control pada siswa SMAN 10 Padang tersebut.

2. Perfeksionis $\left(\mathrm{X}_{2}\right)$

Deskripsi data perfeksionisyang berjumlah 235 siswa, dapat dilihat pada Tabel 2.

Tabel 2. Distribusi Frekuensi dan Persentase Perfeksionis $\left(\mathrm{X}_{2}\right)$

\begin{tabular}{|c|c|c|c|}
\hline Kategori & Interval Skor & $\mathrm{f}$ & $\%$ \\
\hline Sangat Tinggi (ST) & $\geq 172$ & 1 & 0,4 \\
\hline Tinggi (T) & $139-171$ & 89 & 37,9 \\
\hline Sedang (S) & $106-138$ & 140 & 59,6 \\
\hline Rendah $(\mathrm{R})$ & $73-105$ & 4 & 1,7 \\
\hline Sangat Rendah (SR) & $\leq 72$ & 1 & 0,4 \\
\hline \multicolumn{2}{|c|}{ Keseluruhan } & 235 & 100 \\
\hline
\end{tabular}

Tabel 2 memperlihatkan bahwa siswa SMAN 10 Padang memiliki perfeksionis sedang. Namun dengan demikian, masih terdapat variasi skor perfeksionis pada siswa SMAN 10 Padang tersebut.

3. Prokrastinasi Akademik (Y)

Deskripsi data prokrastinasi akademik yang berjumlah 235 siswa, dapat dilihat pada Tabel 3.

Tabel 3. Distribusi Frekuensi dan PersentaseProkrastinasi Akademik Siswa (Y)

\begin{tabular}{|c|c|c|c|}
\hline Kategori & Interval Skor & f & $\mathbf{\%}$ \\
\hline Sangat Tinggi (ST) & $\geq 164$ & 1 & 0,4 \\
\hline Tinggi (T) & $133-163$ & 93 & 39,6 \\
\hline Sedang (S) & $102-132$ & 141 & 60 \\
\hline Rendah (R) & $71-101$ & 0 & 0 \\
\hline Sangat Rendah (SR) & $\leq 70$ & 0 & 0 \\
\hline \multicolumn{2}{|r|}{ Keseluruhan } & $\mathbf{2 3 5}$ & $\mathbf{1 0 0}$ \\
\hline
\end{tabular}


Tabel 3 tersebut memperlihatkan bahwa sebagian besar siswa melakukan prokrastinasi akademik berada pada kategori sedang. Namun dengan demikian, masih terdapat variasi skor prokrastinasi akademik pada siswa SMAN 10 Padang yaitu tinggi dan sangat tinggi. Variasi skor tersebut tentu perlu untuk diperhatikan agar semua siswa dapat menghindari dan mengarahkan perilaku prokrastinasi akademik ke arah positif.

\section{Pengujian Persyaratan Analisis Data}

Uji persyaratan analisis yang dilakukan pada penelitian ini adalah uji normalitas, uji linieritas, dan uji multikolinieritas. Hasil uji normalitas menunjukkan data berdistribusi normal. Selanjutnya, dari hasil uji linieritas diketahui data dinyatakan linier. Kemudian, hasil uji multikolinieritas menunjukkan tidak terjadi multikolinieritas.

\section{Pengujian Hipotesis Penelitian}

1. Kontribusi Locus of Control dan Perfeksionis terhadap Prokrastinasi Akademik

Hasil analisis kontribusi locus of control terhadap prokrastinasi akademik dapat dilihat pada Tabel 4.

Tabel 4. Hasil Uji Koefisien RegresiSederhana Locus of Control $\left(\mathrm{X}_{1}\right)$ terhadap Prokrastinasi Akademik (Y)

\begin{tabular}{|c|c|c|}
\hline Variabel & $\mathrm{R}$ & $\mathrm{R}$ Square \\
\hline $\mathrm{X}_{\mathrm{l}}-\mathrm{Y}$ & 0,462 & 0,213 \\
\hline
\end{tabular}

Tabel 4 menunjukkan bahwa locus of control berkontribusi secara signifikan terhadap prokrastinasi akademik sebesar $21,3 \%$.

2. Kontribusi Perfeksionis terhadap Prokrastinasi Akademik

Hasil analisis kontribusi perfeksionis terhadap prokrastinasi akademik dapat dilihat pada Tabel 5.
Tabel 5. Hasil Uji Koefisien Regresi Sederhana Perfeksionis $\left(\mathrm{X}_{2}\right)$ terhadap Prokrastinasi Akademik (Y)

\begin{tabular}{|c|c|c|}
\hline Variabel & $\mathrm{R}$ & R Square \\
\hline $\mathrm{X} 2-\mathrm{Y}$ & 0,342 & 0,117 \\
\hline
\end{tabular}

Tabel 5 menunjukkan bahwa perfeksionis berkontribusi secara signifikan terhadap prokrastinasi akademik sebesar $11,7 \%$.

3. Kontribusi Locus of Control dan Perfeksionis terhadap Prokrastinasi Akademik

Hasil analisis kontribusi locus of control dan perfeksionis terhadap prokrastinasi akademik dapat dilihat pada Tabel 6 .

Tabel 6. Hasil Uji Koefisien Regresi Ganda Locus of Control $\left(\mathrm{X}_{1}\right)$ dan Perfeksionis $\left(\mathrm{X}_{2}\right) \quad$ terhadap Prokrastinasi Akademik (Y)

\begin{tabular}{|c|c|c|}
\hline Variabel & $\mathbf{R}$ & R Square \\
\hline $\mathrm{X}_{1} \mathrm{X}_{2}-\mathrm{Y}$ & 0,495 & 0,245 \\
\hline
\end{tabular}

Tabel 6 menunjukkan bahwa secara bersama-sama locus of control dan perfeksionis berkontribusi secara signifikan terhadap prokrastinasi akademik sebesar $24,5 \%$. Kemudian, $75,5 \%$ dijelaskan oleh faktor lain yang mempengaruhi prokrastinasi akademik.

\section{PEMBAHASAN}

\section{Locus of Control}

Hasil penelitian menunjukkan bahwa kecenderungan locus of control siswa berada pada kategori internal, atau dapat dipersentasekan sebesar 63\%, sedangkan pada kategori eksternal, yaitu sebesar $37 \%$. Siswa dengan kecenderungan internal locus of control akan meyakini bahwa apa yang dicapai dalam kehidupannya termasuk dalam pencapaian belajarnya adalah hasil usahanya sendiri, sedangkan siswa yang memiliki kecenderungan external locus of control, 
akan meyakini bahwa segala sesuatu yang dicapainya tidak terlepas dari faktor nasib dan keberuntungan yang berada di luar kendali dirinya.

Siswa dengan internal locus of control dalam belajar akan lebih aktif untuk memperoleh ilmu pengetahuan. Siswa meyakini bahwa nilai yang diperolehnya dalam belajar akan setimpal dengan usaha yang dilakukannya, sehingga siswa akan selalu berusaha dalam mendapatkan apa yang menjadi targetnya dalam kehidupan, khususnya dalam belajar.

Hasil penelitian Saputra \& Satiningsih (2013) menunjukkan terdapat pengaruh yang signifikan antara internal locus of control dan kecerdasan emosi terhadap kemampuan pemecahan masalah. Hal ini, dapat disimpulkan bahwa mahasiswa yang memiliki kecenderungan internal locus of control mampu memecahkan masalah yang terjadi pada dirinya, mampu bertanggung jawab atas apa yang dilakukan dan lebih percaya pada kemampuan dirinya, termasuk kemampuan dalam belajar.

Berdasarkan penelitian ini, Guru BK/Konselor diharapkan dapat membantu siswa, menganalisis kebutuhan mengenai kecenderungan locus of control external pada siswa agar perlu penanganan lebih lanjut melalui layanan yang ada. Selanjutnya, analisis kebutuhan ini akan dijadikan dasar penyusunan program pelayanan $\mathrm{BK}$ di sekolah. Guru BK/Konselor diharapkan dapat mengarahkan kecenderungan external locus of control menjadi kecenderungan internal locus of control.

\section{Perfeksionis}

Hasil penelitian menunjukkan bahwa tingkat perfeksionis siswa secara rata-rata berada pada kategori sedang atau didapat sebesar $63,75 \%$. Hasil penelitian ini relevan dengan hasil penelitian Srantih (2014) kategorisasi pada subjek perfeksionis sebesar $71,05 \%$, berada pada kategori sedang. Hal ini menunjukkan bahwa perfeksionis siswa masih dalam keadaan wajar atau normal dan tidak mengarah kepada perfeksionis yang neorotik/negatif.

Menurut LaForge (2005) perfeksionis menuntut segalanya serba sempurna dan terkadang memiliki harapan yang tidak realistis. Perfeksionis membuat siswa sulit menyelesaikan tugas karena merasa tidak mampu untuk mencapai standar yang tinggi dengan berbagai tuntutan yang dirasakan dari lingkungan yang ada di sekitarnya, termasuk significant other.

Hasil penelitian Christopher \& Shewmaker (2010) menemukan bahwa antara depresi dengan perfeksionis memiliki hubungan yang positif pada anak berbakat, artinya semakin tinggi tingkat defresi siswa maka akan semakin tinggi pula perfeksionis yang dimilikinya. Selanjutnya, hasil penelitian Jayanti \& Widayat (2014) menunjukkan terdapat hubungan yang signifikan antara tuntutan orangtua terhadap prestasi dengan perfeksionis pada anak berbakat. Hal tersebut menunjukkan bahwa semakin tinggi tuntutan orangtua terhadap prestasi, maka akan semakin tinggi tingkat perfeksionis siswa.

Berdasarkan penelitian ini, Guru BK/Konselor diharapkan dapat membantu siswa, menganalisis kebutuhan mengenai perfeksionis pada kategori tinggi dan sangat tinggi agar perlu penanganan lebih lanjut melalui layanan yang ada. Selanjutnya, analisis kebutuhan ini akan dijadikan dasar penyusunan program pelayanan $\mathrm{BK}$ di sekolah. Guru BK/Konselor diharapkan dapat mengarahkan perfeksionis neorotik menjadi perfeksionis normal atau positif.

\section{Prokrastinasi Akademik}

Hasil penelitian menunjukkan bahwa secara rata-rata tingkat prokrastinasi yang dilakukan siswa berada pada kategori sedang dengan persentase sebesar $67 \%$. Artinya, siswa masih melakukan prokrastinasi akademik di sekolah, seperti menunda-nunda dalam mengerjakan tugas. Hasil analisis 
deskriptif data menunjukkan pada indikator menunda untuk memulai menyelesaikan PR, menunda menyelesaikan PR, lambat untuk memulai mengerjakan PR, tidak dapat mengefektifkan waktu belajar, keinkonsistenan dalam mengerjakan PR, dan penolakan dalam menghindarkan waktu belajar memulai dan menyelesaikan PR berada pada kategori sedang, sedangkan pada indikator lainnya, yaitu kesulitan dalam memenuhi jadwal belajar, dan bermain berada pada kategori tinggi.

Hasil penelitian ini relevan dengan hasil penelitian Sagita (2015) yang menunjukkan pada deskripsi data prokrastinasi akademik mahasiswa berada kategori sedang. Prokrastinasi akademik adalah penundaan yang dilakukan secara sengaja dan terus menerus dilakukan dalam menyelesaikan tugas, baik untuk memulai maupun menyelesaikan tugas yang berhubungan dengan bidang akademik (Ghufron \& Risnawati, 2014).

Prokrastinasi akademik yang dilakukan siswa menjadi sebuah strategi ketika berhadapan dengan masalah atau situasi yang menimbulkan stres. Siswa banyak gagal dalam mengerjakan tugas karena penundaan yang mereka lakukan. Penundaan dalam mengerjakan PR/tugas akan memberikan dampak negatif bagi siswa yang sering disebut prokrastinasi disfungsional, yaitu apabila siswa menunda-nunda mengerjakan $\mathrm{PR} /$ tugas tidak mempunyai tujuan yang pasti, maka bisa merugikan kepada diri siswa sendiri terutama meningkatkan prestasi belajar. Namun, penundaan ini bisa ke arah positif yang sering disebut prokrastinasi fungsional, yaitu apabila penundaan disertai alasan yang kuat, mempunyai tujuan pasti sehingga tidak merugikan. Bahkan, berguna untuk melakukan suatu upaya konstruktif agar suatu tugas dapat diselesaikan dengan baik (Risnawita \& Ghufron, 2014).

Hasil penelitian Akinsola \& Tella (2007) menunjukkan bahwa terdapat hubungan yang signifikan antara prokrastinasi akademik dan prestasi belajar. Selanjutnya, hasil penelitian Adesina,
Williams, \& Aremu (2011) menunjukkan bahwa siswa yang melakukan prokrastinasi akademik dapat memberi sumbangan yang negatif terhadap prestasi belajar siswa di sekolah. Maksudnya, apabila siswa melakukan penundaan ketika mengerjakan tugas, maka siswa cenderung mendapatkan hasil belajar rendah, ataupun sebaliknya, prokrastinasi siswa rendah maka siswa cenderung mendapatkan hasil belajar tinggi di sekolah.

Permasalahan ini akan menjadi semakin kompleks apabila tidak ditangani. Kemudian, pada kategori tinggi perlu penanganan lebih mendalam agar siswa dapat mengarahkan prokrastinasi kepada yang positif. Mengingat begitu seringnya terjadi prokrastinasi akademik yang dilakukan siswa, maka temuan ini seharusnya ditindaklanjuti oleh Guru BK/Konselor untuk mengarahkan siswa agar mengurangi bahkan mengarahkan perilaku prokrastinasi akademik tersebut ke arah yang positif melalui berbagai pelayanan konseling yang diberikan kepada siswa.

\section{Kontribusi Locus of Control terhadap Prokrastinasi Akademik}

Berdasarkan hasil temuan penelitian, bahwa locus of control berkontribusi secara signifikan terhadap prokrastinasi akademik sebesar 21,3\%. Artinya, Siswa yang memandang bahwa kehidupannya ditentukan oleh perilakunya sendiri akan lebih percaya diri dan gigih dalam mencapai tujuannya seperti dalam belajar, karena dengan mempercayai bahwa setiap usaha yang dilakukan akan mendapatkan hasil yang diharapkan, baik dalam mengerjakan tugas dengan tepat waktu untuk mencapai prestasi dan akan dapat mengurangi perilaku prokrastinasi siswa. Siswa yang memiliki keyakinan bahwa dirinya ikut serta mempengaruhi segala hasil yang dicapai dalam hidupnya, tentu juga memiliki kekuatan dalam mencapai prestasi yang diinginkan.

Hasil penelitian ini sesuai dengan penelitian Hampton (2005) tentang locus of 
control and procrastination dalam penelitian ini menunjukkan hubungan yang signifikan antara prokrastinasi akademik dan locus of control. Siswa yang memiliki skor tinggi pada prokrastinasi menunjukkan orientasi external locus of control, dan sebaliknya mereka yang mendapat skor rendah dalam prokrastinasi menunjukkan orientasi internal locus of control. Selanjutnya, Beck, Koons, \& Migram (dalam Akinsola \& Tella, 2007) menemukan bahwa siswa dengan internal locus of control menunjukkan kurang melakukan prokrastinasi akademik dibandingkan dengan siswa yang memiliki kecenderungan external locus of control. Kemudian, hasil penelitian Jansen\&Carton (1999) mengungkapkan bahwa siswa yang memiliki internal locus of control tidak sering terlibat dalam penundaan, dan menyelesaikan tugas lebih awal dibandingkan dengan siswa yang memiliki external locus of control.

\section{Kontribusi Perfeksionis terhadap Prokrastinasi Akademik Siswa}

Berdasarkan hasil temuan penelitian, diketahui bahwa perfeksionis berkontribusi secara signifikan terhadap prokrastinasi akademik sebesar $11,7 \%$. Artinya, perfeksionis memiliki peran dalam prokrastinasi akademik yang dilakukan oleh siswa. Siswa yang ingin mengerjakan tugas dengan sangat baik akan menunda untuk melakukannya karena cemas apabila tugas yang dikerjakannya dirasa belum sempurna, seperti yang diharapkan.Hasil penelitian ini sesuai dengan hasil penelitian Ananda \& Mastuti (2013) yang menunjukkan bahwa terdapat pengaruh yang signifikan antara perfeksionis terhadap prokrastinasi akademik pada siswa program akselerasi sebesar $18 \%$. Perfeksionis membuat orang malas mengerjakan tugas karena tidak mencapai standar tinggi yang telah dibuatnya.

Hewitt \& Flett (1991) perfeksionis adalah keinginan untuk mencapai kesempurnaan, yang diikuti oleh standar yang tinggi terhadap diri, standar yang tinggi untuk orang lain, dan percaya bahwa orang lain punya pengharapan kesempurnaan dari dirinya. Onwuegbuzie (2000) mengungkapkan bahwa perfeksionis dengan prokrastinasi akademik berkaitan dalam usaha untuk menghasilkan sesuatu yang sempurna.

Hasil penelitian Flett, Blankstein, Hewitt, \& Koledin (1992) ditemukan bahwa perfeksionis memiliki hubungan dengan prokrastinasi akademik dan lebih bergantung kepada konteks sosial. Lebih lanjut, Haycock (dalam Steel, 2007) mengatakan hanya $7 \%$ individu yang perfeksionis memberi kontribusi pada prokrastinasi akademik.

\section{Kontribusi Locus of Control dan Perfeksionis terhadap Prokrastinasi Akademik Siswa}

Hasil penelitian menunjukkan, bahwa locus of control dan perfeksionissecara bersama-samaberkontribusi secara signifikan terhadap prokrastinasi akademik sebesar 24,5\%. Artinya, semakin external locus of control dan semakin tinggi perfeksionis, maka semakin tinggi prokrastinasi akademik siswa, dan begitu pula sebaliknya, semakin internal locus of control dan semakin rendah perfeksionis maka semakin rendah pula prokrastinasi akademik siswa.

Berdasarkan hasil penelitian yang diperoleh, locus of control dan perfeksionis memberikan kontribusi terhadap prokrastinasi akademik yang dilakukan siswa, jika dibandingkan antara keduanya maka locus of control sedikit lebih tinggi nilaikorelasinya. Namun, jika dilihat dari analisis regresi ganda, nilai koefisien uji $\mathrm{t}$ locus of control lebih besar dibanding nilai koefisien uji t perfeksionis. Hilangnya makna perfeksionis untuk memprediksi atau menjelaskan prokrastinasi akademik diduga karena ditekan oleh locus of control.

Hal ini didukung oleh pendapat Kerlinger (2002:951) yang menjelaskan "Jika korelasi-korelasi antara variabelvariabel bebas semuanya nol atau menghampiri nol, penafisiran akan menjadi sangat disederhanakan". Akan tetapi, banyak atau hampir semua variabel yang 
dikorelasikan dengan suatu variabel terikat juga berkorelasi antara yang satu dengan yang lain.

Selanjutnya, Lay (dalam Ferrari, Johnson, \& McCown, 1995) menjelaskan bahwa prokrastinasi akademik secara sederhana menjadi tendensi keseluruhan atau kebiasaan untuk melakukan penundaan terhadap sesuatu untuk mencapai suatu tujuan tertentu. Penundaan ini bisa mengganggu keberhasilan pribadi dan akademis siswa. Prokrastinasi akademik sangat mengganggu kegiatan belajar siswa dan menghambat pencapaian prestasi.

Berbagai faktor yang telah diuraikan pada bab sebelumnya, salah satunya locus of control. Menurut Zulkaida, Kurniati, \& Retnaningsih (2007) siswa dengan kecenderungan internal locus of control, mempunyai anggapan bahwa keterampilan, kemampuan, dan usaha mampu menentukan pencapaian dalam hidup mereka termasuk dalam belajar. Siswa dengan kecenderungan internal locus of control lebih meyakini bahwa setiap usaha yang dilakukan dalam mengerjakan tugas akan mencapai hasil yang diharapkan.

Hasil penelitian Hampton (2005) tentang locus of control and procrastination dalam penelitian ini menunjukkan hubungan yang signifikan antara prokrastinasi akademik dan locus of control.

Lebih lanjut, Burka \& Yuen (2008) menjelaskan faktor yang mempengaruhi munculnya perilaku prokrastinasi akademik adalah perfeksionis. Prokrastinator membuat keinginan yang tidak realistis terhadap diri sendiri. Tuckman (dalam Gunawinata, Nanik \& Lasmono, 2008) menjelaskan bahwa seorang prokrastinator adalah individu yang gemar mencari kesenangan dan akan berusaha menghindari segala hal yang dapat memberi tekanan terhadap dirinya. Dengan begitu, individu yang perfeksionis akan melakukan penghindaran dengan melakukan prokrastinasi sebagai bentuk coping terhadap segala tuntutan dan tekanan yang dirasakan.

\section{KESIMPULAN}

Berdasarkan temuan dan pembahasan hasil penelitian, maka dapat dikemukakan kesimpulan sebagai berikut:

1. Gambaran locus of control siswa SMAN 10 Padang berada pada kategori internal. Artinya, siswa masih meyakini bahwa peristiwa yang menimpa dirinya ditentukan oleh siswa itu sendiri.

2. Gambaran perfeksionis siswa SMAN 10 Padang berada pada kategori sedang. Artinya, siswa masih banyak memiliki perfeksionis yang normal, yaitu siswa masih mengarah kepada perfeksionis yang positif.

3. Gambaran prokrastinasi akademik siswa SMAN 10 Padang berada pada kategori sedang. Artinya, siswa masih ada yang menunda ketika mengerjakan PR/tugas yang diberikan guru.

4. Locus of control berkontribusi secara signifikan terhadap rokrastinasi akademik siswa sebesar 21,3\% ( $\mathrm{R}=$ $\left.0,462, \mathrm{R}^{2}=0,213\right)$. Artinya, tinggi rendahnya prokrastinasi akademik dijelaskan oleh tinggi rendahnya locus of control.

5. Perfeksionis berkontribusi secara signifikan terhadap prokrastinasi akademik sebesar $11,7 \%\left(\mathrm{R}=0,342, \mathrm{R}^{2}\right.$ $=0,117)$. Artinya, tinggi rendahnya prokrastinasi akademik dijelaskan oleh tinggi rendahnya perfeksionis.

6. Locus of control dan perfeksionis secara bersama berkontribusi terhadap prokrastinasi akademik siswa sebesar $24,5 \%\left(\mathrm{R}=0,495, \mathrm{R}^{2}=0,245\right)$. Artinya tinggi rendahnya prokrastinasi akademik tidak hanya dijelaskan oleh dua variabel saja (locus of control dan perfeksionis), akan tetapi, juga dijelaskan oleh faktor lain.

\section{SARAN}

Berdasarkan hasil penelitian, pembahasan, dan kesimpulan yang telah dikemukakan sebelumnya, maka terdapat beberapa saran yang dapat direkomendasikan kepada beberapa pihak sebagai berikut. 


\section{Siswa SMAN 10 Padang}

Diharapkan agar dapat mengurangi bahkan perilaku prokrastinasi akademik mengikuti berbagai layanan bimbingan dan konseling, serta memiliki kecenderunganlocus of control menjadi internal dan mengurangi sikap perfeksionis yang tinggi dan sangat tinggi pada diri siswa. 2. Guru BK/Konselor

Disarankan untuk membantu siswa dalam mengurangi perilaku prokrastinasi akademikdalam mengerjakan tugas yang dilakukan siswa dengan memfokuskan pada peningkatan locus of control menjadi internal dan mengarahkan perfeksionis yang tinggi dan sangat tinggi kepada perfeksionis normal/positif. Serta hasil penelitian ini dapat dijadikan sebagai analisis kebutuhan siswa bagi Guru BK dalam pembuatan program layanan bimbingan dan konseling. Guru BK/Konselor dapat bekerja sama dengan personel sekolah lainnya untuk melaksanakan program pelayanan $\mathrm{BK}$ di sekolah.

3. Guru Mata Pelajaran

Diharapkan kepada Guru Mata Pelajaran selalu memperhatikan siswa yang melakukan prokrastinasi akademik, sehingga siswa tidak melakukan penundaan dalam belajar, dan dalam pengumpulan tugas. Kemudian, melihat berbagai faktor yang menyebabkan siswa melakukan prokrastinasi akademik, seperti locus of control dan perfeksionis. Guru Mata Pelajaran juga bekerja sama dengan Guru BK/Konselor serta orangtua siswa agar lebih memperhatikan tugas yang diberikan guru.

4. Kepala Sekolah

Diharapkan kepada Kepala Sekolah agar melengkapi sarana dan prasarana sekolah, sehingga program BK bisa terlaksana dengan baik, dan memotivasi Guru BK/Konselor agar dapat meningkatkan keterampilan dalam membuat program BK yang sesuai dengan kebutuhan siswa. Mengajak seluruh personel sekolah untuk bekerja sama dalam menyukseskan pelayanan BK di sekolah, mengarahkan siswa agar dapat secara aktif dalam mengikuti layanan BK di sekolah sesuai dengan permasalahan yang mereka alami, khususnya dalam mengurangi dan menghilangkan prokrastinasi akademik yang dilakukan siswa.

5. Peneliti Selanjutnya

Sebagai dasar penelitian lanjutan dengan meneliti variabel lain dan subjek penelitianyang berbeda, yang diperkirakan berkontribusi terhadap prokrastinasi akademik siswa.

\section{DAFTAR RUJUKAN}

Adesina, F. T., Williams, T. M., \& Aremu, F. T. 2011. Influence of Academic Procrastination and Personality Types on Academic Achievement and Efficacy of in School Adolescents in Ibadan. Journal of Ife PsychologIA, Vol 19: Department of Guidance \& Counselling University of Ibadan, Nigeria.

Akinsola, M. K., Tella, A., \& Tella, A. 2007.Correlates of Academic Procrastination and Mathematics Achievement of University Undergraduate Students.Eurasia Journal of Mathematics, Science \& Technology Education, 3(4), 363370: University of Botswana, Gaborone, BOTSWANA.

Ananda, N. Y., \& Mastuti, E. 2013. "Pengaruh Perfeksionis terhadap Prokrastinasi Akademik pada Siswa Program Akselerasi". Jurnal Psikologi Pendidikan dan Perkembangan, 2 (3): 226-231.

Burka, J. B., \& Yuen, L. M. 2008. Procrastination: Why you do it, what to do about it no. United States of America: Da Capo Press A Member of the Perseus Books Group.

Christopher, M. M., \& Shewmaker, J. 2010. "The Relationship of Perfectionism to 
Affective Variables in Gifted and Highly Able Children". Journal of Personality and Social Psychology, 33 (3): 22-29.

Ferrari, J. R., Johnson, J. L., \& McCown, W. 1995. Procrastination and Task Avoidance: Theory, research, and treatment. New York: Plenum Press.

Gafni, R., \& Geri, N. 2010. "Time Management: Procrastination tendency in individual and collaborative tasks". The Open University of Israel. Interdisciplinary Journal of Information, Knowledge, \& Management, 5 (2): 115-125.

Gohil, E. 2014. "Procrastination and SelfEsteem A Gender Based Study".Lecturer, Department of Psychology, University of Jammu, Jammu and Kashmir.Global Journal of Interdisciplinary Social Sciences, 3 (3): 91-95.

Gunawinata, V. A., Nanik.,\& Lasmono, H. K. 2008. "Perfeksionisme, Prokrastinasi Akademik \& Penyelesaian Skripsi Mahasiswa". Anima, Indonesian Psychological Journal, 2 (1): 8-15.

Hampton, A. E. 2005. "Locus of Control and Procrastination". Journal Epistimis, 4 (1): 3-5, (Online), (http://www.capital.edu/68/Arts-and Sciences/23608/, diakses 21 April $\underline{2013}$ ).

Hewitt, P. L., \& Flett, G. L. 1991. "Perfectionism in Self and Social Context: Conceptualization, assessment, and association with psychopathology", Journal of Personality and Social Psychology, 60 (3): 456-470.
Jansen, T., \& Carton, J. S. 1999. "The Effects of Locus of Control and Task Difficulty on Procrastination". Journal of Genetic Psychology, 160 (4): 63-80.

Jayanti, R., \& Widayat, I. W. 2014. "Hubungan antara Tuntutan Orangtua terhadap Prestasi dengan Perfeksionis pada Anak Berbakat di SMA Negeri 1 Gresik". Jurnal Psikologi Klinis dan Kesehatan Mental, 3 (3): 153158.

Kerlinger, F. N. 2002. Asas-asas Penelitian Behavioral. Terjemahan oleh Landung R. Simatupang. Yogyakarta:Gadjah Mada UniversitasPress

LaForge, M. 2005. "Applying Explanatory Style to Academic Procrastination". Journal of the Academic of Business Aducation, 6 (3): 55-80.

Loice, M. C. 2014. "The Influence of Locus of Control on Employees' Perceptions of the Effectiveness of Performance Appraisal at Kenya Revenue Authority (Southern Region)". A Research Project Submitted in Partial Fulfillmentof the Requirements for the Award of the Degree of Master of Business Administration (MBA), (Online), (www.erepository.uonbi.ac.ke/.../Mu tai_ The\%20influen,diakses 25 Desember 2014).

Nugrasanti, R. 2006. "Locus of Control dan Prokrastinasi Akademik Mahasiswa". Jurnal Provitae, 2 (1): 25-33.

Onwuegbuzie, A. J. 2000. "Academic Procrastinators and Perfectionistic Tendencies among Graduate Students". Journal of Social Behavior and Personality, 15 (5): 103-109. 
Risnawita, R., \& Ghufron, M.N. 2014.Teoriteori Psikologi. Jakarta: Ar-Ruzz Media.

Rotter, J. B. 1966. "Generalized Expectancies for Internal Versus External Control of Reinforcement".American Psychological Association, 80 (1): 128.

Rumiani. 2006. "Prokrastinasi Akademik Ditinjau dari Motivasi Berprestasi dan Stres Mahasiswa". Jurnal Psikologi Universitas Diponegoro Semarang, 3 (2): 37-48.

Sagita, D. 2015. "Hubungan Self Efficacy, Motivasi Berprestasi, dan Prokrastinasi Akademik dengan Stress Akademik Mahasiswa".Tesis tidak diterbitkan. Padang: Program Studi S2 Bimbingan dan Konseling Fakultas Ilmu Pendidikan Universitas Negeri Padang.

Saputra, V. A., \& Satiningsih. 2013. "Pengaruh Internal Locus of Control dan Kecerdasan Emosi terhadap Kemampuan Pemecahan Masalah pada Mahasiswa Fakultas Ilmu
Pendidikan Universitas Negeri Surabaya". Jurnal Penelitian Psikologi, (Online), 1(2):14-30.

Savira, F., \& Suharsono, Y. 2013. "SelfRegulated Learning (SRL) dengan Prokrastinasi Akademik Siswa". Jurnal Ilmiah Psikologi Terapan, 1 (1): 65-74.

Solomon, L. J., \& Rothblum, E. D. 1984. "Academic Procrastination: Frequency and cognitive behavioral correlates". Journal of Counseling Psychology, 31 (4): 503-509.

Yang, H., \& Stoeber, J. 2012. “The Physical Appearance Perfectionism Scale: Development and preliminary validation". Journal of Psychopathology and BehavioralAssessment, 34 (1): 69-83.

Zulkaida, A., Kurniati, N. T., \& Retnaningsih. 2007. "Pengaruh Locus of Control dan Efikasi Diri terhadap Kematangan Karir Siswa Sekolah Menengah Atas (SMA)". Jurnal ProsidingPesat, 2 (2): 1-4. 